\title{
Pengembangan Model Pembelajaran Outbound pada Pendidikan Jasmani dalam Meningkatkan Kesegaran Jasmani Siswa
}

\author{
Humaedi $^{\text {a, } 1}$, Hendra Iskandar ${ }^{\text {a, }}$, Ikhwan Abduh ${ }^{\text {a, 3* }}$ \\ ${ }^{a}$ Prodi Pendidikan Jasmani Kesehatan dan Rekreasi Jurusan Ilmu Pendidikan Fakultas Keguruan dan Ilmu \\ Pendidikan Universitas Tadulako, Indonesia \\ ${ }^{1}$ hum771@gmail.com*; ${ }^{2}$ hendraiskandarh@gmail.com ; ${ }^{3}$ ikhwan.abduh09@gmail.com \\ *korespondensi penulis
}

\section{Informasi artikel \\ Received : \\ Januari, 2019. \\ Revised : \\ Maret,2019. \\ Publish : \\ Agustus, 2019. \\ Kata kunci: \\ Out Bound \\ Kesegaran Jasmani}

\begin{abstract}
ABSTRAK
Tujuan penelitian ini adalah Menjadi media atau model pembelajaran yang dapat digunakan untuk pembelajaran pendidikan jasmani, media pembelajaran Outbond juga diharapkan mampu meningkatkan kompetensi kebugaran jasmani siswa. Jenis penelitian yang akan dilakukan adalah jenis penelitian pengembangan (Research and Development (R\&D). tahapan penelitian dimulai dari Penelitian awal dan pengumpulan informasi, Pengembangan produk awal, Uji lapangan awal (validasi ahli), Uji coba kelompok kecil, apabila dibutuhkan perbaikan maka dilakukan revisi pertama, dan terakhir melakukan uji coba kelompok besar. Nilai rata-rata perolehan tes kesegaran jasmani siswa sebesar 11,67 yang berarti tingkat kesegaran jasmani siswa kelas V SDN Terpadu Madani masih berklasifikasi sedang, namun pada beberapa siswa telah mangalami perubahan kesegaran jasmani yang baik. Sehingga model pembelajaran outbound yang dikembangkan telah baik dan dapat di gunakan dalam pengembangan tingkat kesegaran jasmani siswa. Sebagai variasi dalam pembelajaran pendidikan jasmani kami merekomendasikan agar model pembelajaran dapat digunakan sebagai alternative pembelajaran yang lebih mengedepankan gerak dan keaktifan peserta didik.
\end{abstract}

\begin{abstract}
The purpose of this study is to become a media or learning model that can be used for physical education learning, Outbound learning media are also expected to be able to improve students' physical fitness competencies. The type of research that will be conducted is the type of research and development $(R \& D)$. The research phase starts from the initial research and information collection, initial product development, initial field testing (expert validation), small group trials, if needed repairs, revisions are made. first, and lastly do a large group trial. The average score of student physical fitness test is 11.67, which means the level of physical fitness of fifth grade students of Integrated Madani Elementary School is still classified, but in some students has experienced a change in good physical fitness. So that the outbound learning model developed has been good and can be used in developing the level of physical fitness of students As a variation in learning physical education we recommend that the learning model be used as an alternative learning that prioritizes the movements and activeness of students.
\end{abstract}

$\overline{\text { Copyright }(2019 \text { (Humaedi, Hendra Iskandar, Ikhwan Abduh). All Right Reserved }}$

How to Cite: Humaedi, H., Iskandar, H., \& Abduh, I. (2019). Pengembangan Model Pembelajaran Outbound pada Pendidikan Jasmani dalam Meningkatkan Kesegaran Jasmani Siswa. Jurnal Inspirasi Pendidikan, 9(2), 117-122.

This work is licensed under a Creative Commons Attribution-ShareAlike 4.0 International License. Allows readers to read, download, copy, distribute, print, search, or link to the full texts of its articles and allow readers to use them for any other lawful purpose. The journal hold the copyright. 
Jurnal Inspirasi Pendidikan, VOL.9, NO.2, Edisi Agustus 2019

Pengembangan Model Pembelajaran Outbound pada Pendidikan Jasmani dalam Meningkatkan Kesegaran Jasmani Siswa

Humaedi $^{\text {a, } 1}$, Hendra Iskandar ${ }^{\text {a, } 2}$, Ikhwan Abduh a, 3 Hal: $117-122$

\section{Pendahuluan}

Penekanan Pendidikan Jasmani terhadap manusia seutuhnya mempunyai resiko diabaikan karena tuntutan intelektual dan karena kompensasi masyarakat modern yang memberi penghargaan keterampilan intelektual yang lebih tinggi dari pada ketrampilan jasmaniah meskipun harus menanggung resiko. Hal tersebut akan lebih diperparah lagi akibatnya apabila dalam usaha meningkatkan daya dan kekuatan jasmaniah tanpa dilandasi pandangan yang manusiawi seperti halnya merobotkan manusia. Pembelajaran jasmani disekolah hendaknya dapat menjadi sarana peningkatan kualitas jasmani dan rohani siswa sehingga guru dituntut harus memahami dan mengembangkan model pembelajaran yang tepat guna (Mahendra, 2018).

Model pembelajaran konvensional telah banyak di lakukan oleh guru sehingga membutuhkan pembaharuan. Pembelajaran konvensional yang dulunya hanya focus pada penjelesan secara teoritis dan menggunakan system komando, artinya peserta didik hanya akan melakukan pembelajaran sesuai dengan instruksi guru sehingga terkesan kaku dalam pembelajaran. Konsep belajar dengan pendekatan tersebut hanya akan dapat membuat anak kurang gerak, kurang kreatif dan bahkan cenderung membosankan (Fadlillah, Lilif, Wantini, Eliyyil, \& Syifa, 2104). Model permainan out bound merupakan model permainan yang banyak diganderungi oleh anak dan remaja, out bound banyak digemari karena out bound menjadi sarana bermain dan mengekspresikan diri yang lebih leluasa, selain itu out bound juga menggabungkan beberapa jenis permainan dan gerak dasar jasmani sehingga memungkinkan membantu anak atau siswa meningkatkan kesegaran jasmaninya (Gray et al., 2017) Perbedaan yang telihat jelas dengan pembelajaran konvensional adalah keleluasaan peserta didik melakukan proses pembelajaran, melakukan eksplorasi dan berkreasi sehingga akan lebih cenderung aktif dan prose pembelajaran tidak monoton.

Model pembelajaran dengan pendekatan bermain pada mata pelajaran pendidikan jasmani telah ada beberapa yang melakukan penelitian diantaranya pengembangan model pembelajaran gerak dasar melompat melalui permainan lompat bergandeng sehingga siswa dapat meningkatkan aktifitas fisik dan membuat siswa lebih semangat dan senang dalam melakukan pembelajaran penjas(Anggi, Rumini, \& Widyasari, 2013). Permainan out bound juga telah banyak dikembangkan menjadi model pembelajaran yang dapat meningkatkan kreatifitas siswa sekolah dasar, dengan permainan outbound dapat membantu pembentukan karakter, moral dan kreatifitas pada siswa, sehingga dapant meningkatkan kualitas siswa dan mutu pendidikan(Hakim \& Kumala, 2016). Penggunaan outbound sebagai model pembelajaran juga telah digunakan sebagai media pembelajaran bahasa arab sehingga pembejaran tidak hanya terfokus pada pembejaran bahasa arab namun juga pembejaran menjadi menyenangkan dan bersemangat(Ali, 2018). Penggunaam media permainan outbound sebagai sarana pembelajaran pada mata pelajaran penjas.

Perbedaan dengan penelitian yang akan dilakukan adalah pembejalaran akan di desain agar aktifitas fisik yang dianggap dapat meningkatkan kesegaran jasmani di masukkan kedalam jenis permainan. Jenis permainan yang dimaksd adalah berlari bolak balik, menggantung, memanjat, Tujuan penelitian adalah 1) Menjadi media atau model pembelajaran yang dapat digunakan untuk pembelajaran pendidikan jasmani 2)Melalui media pembelajaran Outbond diharapkan mampu meningkatkan kebugaran jasmani siswa.

\section{Metode}

Jenis penelitian pengembangan (Research and Development (R\&D) Borg \& Gall dalam (Winarno, 2011) yang telah dimodifikasi oleh peneliti. Penelitian ini menggunakan desain model pengembangan procedural yang bersifat deskriptif dengan menggambarkan secara umum hasil penelitian dalam bentuk persentase. Subjek penelitian adalah siswa SDN Terpadu Madani Kota Palu dengan rentang umur $10 \mathrm{~s} / \mathrm{d} 12$ tahun sebanyak 30 orang. Instrumen tes yang digunakan adalah menggunakan teknik observasi dan instrument Tes Kesegaran Jasmani Indonesia (TKJI) tahun 2010 yang terdiri dari: 1) lari sprint, 2) gantung angkat tubuh (pull up), 3) baring duduk ( Sit Up), 4) Loncat tegak (vertical jump), 5) lari jarak sedang. Instrumen uji validasi ahli di kembangkan dan buat oleh peneliti . Prosedur pengumpulan data terdiri dari beberapa tahapan yaitu: a) analisis kebutuhan, b) Uji 
Jurnal Inspirasi Pendidikan, VOL.9, NO.2, Edisi Agustus 2019

Pengembangan Model Pembelajaran Outbound pada Pendidikan Jasmani dalam Meningkatkan Kesegaran Jasmani Siswa

Humaedi $^{\text {a, } 1}$, Hendra Iskandar ${ }^{\text {a, } 2}$, Ikhwan Abduh a, 3

ahli (Validasi ahli), c)Uji coba tahap pertama, d) Uji coba tahap kedua. teknik analisis data yang digunakan adalah teknik analisis persentanse dengan rumus $\mathrm{P}=\frac{\sum x}{\sum y} x 100$

\section{Hasil dan pembahasan}

Berdasarkan hasil penelitian yang telah dilakukan maka didapatkan yang dilakukan dalam beberapa tahapan yaitu

1) Analisis kebutuhan

Berdasarkan observasi yang dilakukan sebelum penelitian dapat disimpulkan bahwa model pembelajaran Out Bound berbasis kompetensi dalam pembelajaran penjaskes belum diterapkan dalam proses kegiatan belajar mengajar di SD Terpadu Madani. Diperlukan solusi yang tepat dan bermanfaat untuk menghadapi kendala dan permasalahan yang muncul agar pembelajaran Penjaskes dapat mencapai tujuan dan kompetensi yang diinginkan. Melalui model pembelajaran Out bound berbasis kompetensi yang sudah mencakup materi lari, lompat dan lempar seharusnya memberikan alternatif pilihan media pembelajaran yang lebih beragam dalam memenuhi gaya belajar murid. Disamping itu, model pembelajaran out bound dalam pembelajaran penjaskes dapat memberikan ruang bermain sambil belajar bagi murid untuk membangun pengetahuannya sendiri sehingga akan dapat meningkatkan semangat dan kesegaran jasmani siswa.

2) Uji Validasi Perangkat Oleh Ahli hasil validasi ahli yang dilakukan oleh ahli media pembelajaran, ahli materi dan ahli bahasa

Tabel 4.1 Rangkuman Hasil Validasi Ahli

\begin{tabular}{cccc}
\hline No & Aspek Penilaian & Validator & Keterangan \\
\hline 1 & Ahli Materi & 3,67 & Cukup Valid \\
2 & Ahli Media & 3,6 & Cukup Valid \\
3 & Ahli Bahasa & 4,0 & Valid \\
\hline \multicolumn{2}{c}{ Rata-rata penilaian total } & 3,77 & Valid \\
\hline
\end{tabular}

Hasil validasi oleh ahli media, bahasa dan materi diperoleh rata-rata penilaian yakni 3,77 dengan keterangan "Valid" sehingga perangkat layak digunakan dalam uji coba lapangan.

3) Uji Coba Tahap Pertama

Setelah melakukan pengaplikasian model selanjutnya melihat dampak model pembelajaran yang dilakukan dengan mengukur tingkat kesegaran jasmani siswa.

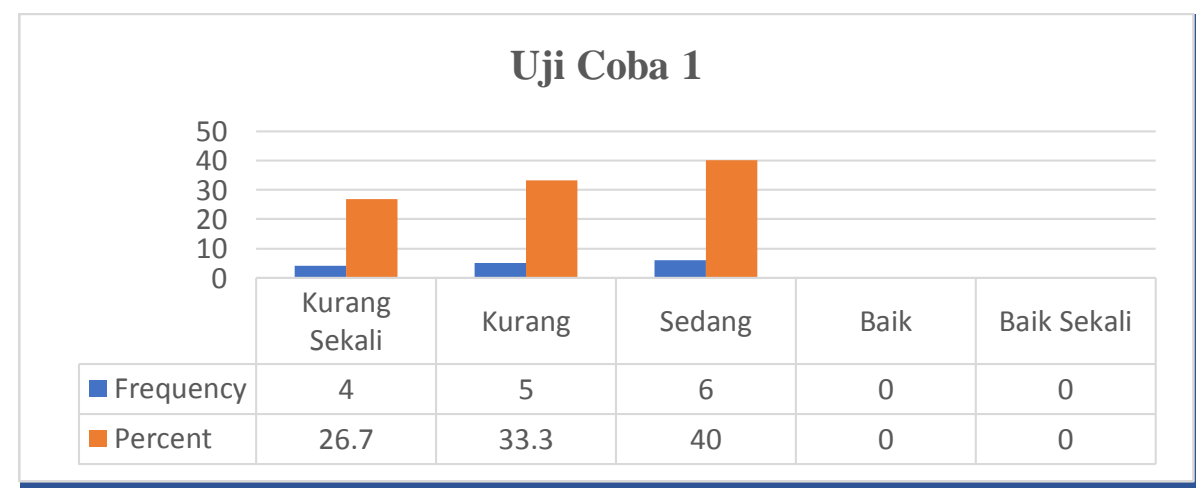

Gambar 1 Diagram Klasifikasi Tingkat Kesegaran Jasmani Siswa SDN Terpadu Madani 
Jurnal Inspirasi Pendidikan, VOL.9, NO.2, Edisi Agustus 2019

Pengembangan Model Pembelajaran Outbound pada Pendidikan Jasmani dalam Meningkatkan Kesegaran Jasmani Siswa

Humaedi $^{\text {a, } 1}$, Hendra Iskandar ${ }^{\text {a, } 2}$, Ikhwan Abduh a, 3

Jumlah siswa dengan tingkat kesegaran jasmani kurang sekali sebanyak 4 orang atau 26.7\%, jumlah siswa dengan klasifikasi kurang sebanyak 5 orang atau 33,3\%, klasifikasi siswa baik tidak ada begitupun dengan klasifikasi siswa yang memiliki kesegaran jasmani baik sekali juga tidak ada

4) Uji Coba tahap Kedua

Kekurangan yang terjadi pada uji coba tahap pertama lebih diminimalisis seperti manajemen waktu pada saat permainan out bound dan aturan permainan yang lebih disederhanakan sehingga mempercepat siswa dalam memahami instruksi yang diberikan. Hasil pengaplikasian model pembelajaran Out bound.

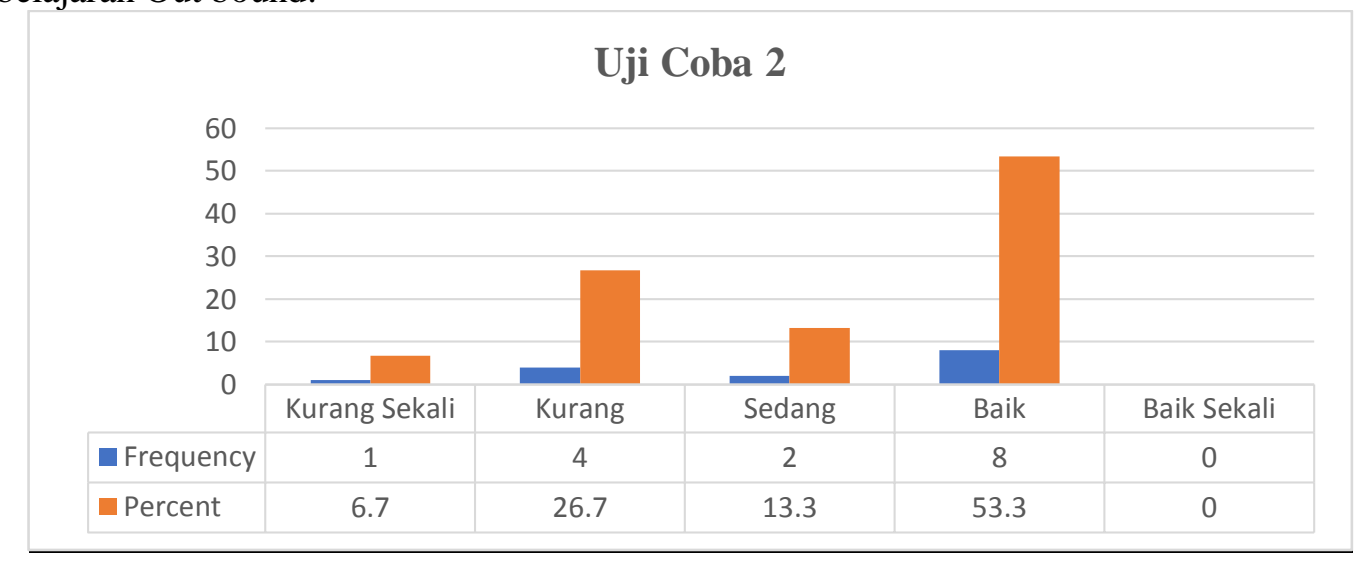

Gambar 2 Diagram Klasifikasi Tingkat Kesegaran Jasmani Siswa SDN Terpadu Madani

Jumlah siswa dengan tingkat kesegaran jasmani kurang sekali telah berkurang yaitu sebanyak 1 orang atau $6.7 \%$, jumlah siswa dengan klasifikasi kurang sebanyak 4 orang atau 26,7\%, klasifikasi siswa sedang sebanyak 2 orang atau 13,3\%, klasifikasi kesegaran jasmani baik sebanyak 8 orang atau $53,3 \%$ dan tidak ada siswa dengan klasifikasi baik sekali.

Hasil peneltian menunjukkan bahwa model pembelajaran out bound memiliki dampak yang baik terhadap kesegaran jasmani siswa hal tersebut terlihat dari data jumlah siswa yang memiliki tingkat kesegaran jasmani dari yang umumnya jumlah siswa lebih banyak pada kategori sedang dan kategori sangat kurang pada uji coba tahap I dan terjadi perubahan jumlah siswa yang memiliki kategori baik dan mengalami pengurangan jumlah siswa pada kategori kurang sekali

Dari rangkaian penelitian yang telah dikakukan didapatkan hasil bahwa model pembelajaran out bound berbasis kompetensi pada pembelajaran penjaskes di SDN Terpadu Madani Palu dapat digunakan sebagai model pembelajaran untuk meningkatkan kesegaran jasmani siswa. Outbound merupakan metode pelatihan untuk pengembangan diri (personal development) dan tim (team development) dalam proses mencari pengalaman melalui kegiatan di alam terbuka (Agusta, Setyosari, \& Sa'dijah, 2018). Outbound tidak hanya dapat dilakukan oleh orang dewasa atau hanya di dalam dunia pekerjaan, tetapi di Indonesia sekarang outbound sudah lebih dikembangkan lagi dengan pembelajaran untuk anak- anak yang masih belia (Andajani, Rahayu, \& Prihatiningrum, 2018; Yunaida \& Rosita, 2018).

Sejalan dengan analisis kebutuhan yang telah dilakukan maka pengumpulan informasi dilakukan sebelum pengembangan model, baik itu karakter siswa, studi literatur mengenai pembelajaran pendidikan jasmani dan kesehatan yang dapat dilakukan dengan berbagai model pembelajaran pada siswa SDN Terpadu Madani kelas V yang kemudian dirumuskan dalam perumusan masalah. Melalui kajian literatur dan analilsis kebutuhan maka diharapkan lahirnya sebuah model pemebelajaran yang memiliki peluang implementatif yang baik. Proses semacam ini, dipertegas oleh (Borg, W.R. \& Gall, M.D. Gall, 1983) bahwa kajian literatur dilakukan untuk mengumpulkan informasi dalam rangka merencanakan dan pengembangan model. Salah satu tujuannya adalah untuk menentukan area kajian dan implementasi model. 
Jurnal Inspirasi Pendidikan, VOL.9, NO.2, Edisi Agustus 2019

Pengembangan Model Pembelajaran Outbound pada Pendidikan Jasmani dalam Meningkatkan Kesegaran Jasmani Siswa

Humaedi $^{\text {a, } 1}$, Hendra Iskandar ${ }^{\text {a, } 2}$, Ikhwan Abduh ${ }^{\text {a, } 3}$ Hal: $117-122$

Dalam pengembangan model ini, telah dirumuskan model hipotetik tentang Pembelajaran penjaskes dengan model pembelajaran out bound berbasis kompetensi. Model ini terdiri dari beberapa aspek seperti perencanaan, penerapan, dan evaluasi. Rumusan model hipotetik ini merupakan hasil riset pada tahap awal pengembangan. Model hipotetik yang telah dirumuskan perlu dilakukan validasi untuk memperoleh model yang memiliki kelayakan isi dan praktis. Berdasarkan validasi isi model hipotetik, diperoleh hasil yang menunjukkan bahwa semua aspek atau struktur yang membangun model dinilai oleh para ahli yang bertindak sebagai validator telah memiliki kelayakan konseptual yang memadai. Hasil validasi ini menunjukkan bahwa pada umumnya validator menyatakan bahwa model ini memiliki kelayakan praktisi atau operasional yang memadai.

Hasil uji validasi yang telah dilakukan dijadikan bahan revisi model sebelum diujikan dilapangan. Selanjutnya dilakukan uji tahap pertama yang melibatkan 15 orang siswa kelas $\mathrm{V}$ untuk mengetahui tingkat kesegaran jasmani siswa. Setelah uji tahap pertama dilaksanakan maka dilanjutkan dengan revisi II hasil klasifikasi kesegaran jasmani siswa dijadikan sebagai bahan analisa dalam melakukan revisi ke dua pada model pembelajaran outbound berbasis kompetensi yang menyatakan bahwa tingkat kesegaran jasmani siswa masih dalam klasifikasi "kurang". Hasil dari revisi II dilanjutkan pada tahap uji tahap kedua yang melibatkan 15 orang siswa yang sama yaitu kelas V. Hasil uji tahap kedua menyatakan bahwa secara rata-rata tingkat kesegaran jasmani siswa dalam klasifikasi "sedang" namun jumlah siswa yang kesegaran jasmani yang berklasifikasi "baik" sudah lebih banyak dari uji coba tahap pertama sehingga pengembangan model pembelajaran out bound berbasis kompetensi valid dan praktis. Dimana dikatakan valid karena telah divalidasi oleh validasi ahli dan dikatakan praktis karena telah dimanfaatkan oleh guru dan siswa dalam pembelajaran pendidikan jasmani dan kesehatan.

Berdasarkan proses dan hasil pengembangan model pembelajaran penjaskes, maka model ini memberikan keyakinan teoritis dan empirik untuk diimplementasikan di sekolah dalam upaya meningkatkan kesegaran jasmani murid di sekolah. Untuk itu perlu dipaparkan keunggulan, kelemahan/keterbatasan model.

\section{Keunggulan Model}

Pada tataran tertentu, pembelajaran penjaskes yang selama ini dilakukan di sekolah bersifat monoton, membosankan, masih menggunakan metode demonstrasi. Model pembelajaran outbound berorentasi studend center learning yang diharapkan siswa dapat lebih aktif dalam pembelajaran sehingga dapat meningkatkan kesegaran jasmani siswa. Model pembelajaran outbound ini sangat baik dalam membentuk karakter siswa agar dapat bersosialisasi dengan teman kelompoknya. selain itu Metode outbound training memungkinkan peserta dalam aktivitasnya melakukan sentuhan-sentuhan fisik dengan latar alam yang terbuka sehingga diharapkan melahirkan kemampuan dan watak serta visi kepemimpinan yang mengandung nilai-nilai kejujuran, keterbukaan, toleransi, kepekaan yang mendalam, kecerdasan serta rasa kebersamaan dalam membangun hubungan antar manusia yang serasi dan dinamis.

\section{Keterbatasan Model}

Keterbatasan model pembelajaran outbound berbasis kompetensi ini adalah model pembejaran seperti ini membutuhkan waktu yang relative lama dan terkadang siswa tidak menyadari sehingga asyik bermain dan setelahnya kelelahan untuk mengikuti mata pelajaran berikutnya, sehingga manajemen waktu memang harus betul-betul di perbaikai bagi guru yang akan menggunakan model pembelajaran ini. Selain itu model permainan out bound harus menggunakan alat yang banyak sehingga sekolah harus memiliki sarana pendukung yang akan menunjang kegiatan out bound yang akan dilakukan sesuai dengan jenis permainannya.

Simpulan ditulis dalam satu paragraf, yang merupakan ringkasan dari hasil dan pembahasan serta menjawab dari tujuan dari penelitian/publikasi. Menekankan pada kebaruan dari penemuan atau pengembangan. Pada bagian ini dapat memuat saran yang disusun untuk kegiatan praktis ataupun penelitian lanjutan berdasarkan hasil kebaruan yang ditemukan.

Berdasarkan pembahasan maka model pembelajaran outbound berbasis kompetensi dapat digunakan sebagai model pembelajaran pendidikan jasmani dan dapat meningkatkan kebugaran jasmani siswa 
Jurnal Inspirasi Pendidikan, VOL.9, NO.2, Edisi Agustus 2019

Pengembangan Model Pembelajaran Outbound pada Pendidikan Jasmani dalam Meningkatkan Kesegaran Jasmani Siswa

Humaedi $^{\text {a, } 1}$, Hendra Iskandar ${ }^{\text {a, } 2}$, Ikhwan Abduh a, 3 Hal: $117-122$

\section{Simpulan}

Berdasarkan hasil penelitian dan pembahasan sebelumnya maka dapat disimpulkan bahwa 1) Model pembelajaran Out Bound valid dan praktis digunakan dalam pembejaran jasmani. 2)Model Pembelajaran outbound dapat meningkatkan kebugaran jasmani siswa yang

\section{Referensi}

Agusta, A. R., Setyosari, P., \& Sa'dijah, C. (2018). Implementasi Strategi Outdoor Learning Variasi Outbound Untuk Meningkatkan Kreativitas Dan Kerjasama Siswa Sekolah Dasar. Jurnal Pendidikan: Teori, Penelitian, Dan Pengembangan, 3(4), 453-459. http://dx.doi.org/10.17977/jptpp.v3i4.10745

Ali, J. (2018). Outbound as The Alternative Method to Have Fun Arabic Learning. 3(2), 244-261. https://doi.org/10.28918/alsinatuna.v3i2.1276

Andajani, E., Rahayu, S., \& Prihatiningrum, A. E. (2018). Sosialisasi Kekompakan Tim Melalui Outbound pada Kelompok Sadar Wisata Desa Mojo Kabupaten Bojonegoro. JPM (Jurnal Pemberdayaan Masyarakat), 3(2), 286-293. https://doi.org/10.21067/jpm.v3i2.2702

Anggi, F. S., Rumini, \& Widyasari, H. (2013). Model Pembelajaran Gerak Dasar Melompat Dalam Penjasorkes Melalui Permainan Lompat Bergandeng Pada Siswa Kelas IV Sekolah Dasar. ACTIVE: Journal of Physical Education, Sport, Health and Recreation, 2(3). https://doi.org/10.15294/active.v2i3.1088

Borg, W.R., \& Gall, M.D. Gall. (1983). Educational Research: An Introduction (Fifth Edition). New York: Longman.

Fadlillah, M., Lilif, M. K. F., Wantini, Eliyyil, A., \& Syifa, F. (2104). Edutainment Pendidikan Anak Usia Dini: Menciptakan Pembelajaran Menarik (1st ed.). Jakarta: Kencana Prenamedia Group.

Gray, T., Hall, T., Downey, G., Jones, B., Truong, S., \& Power, A. (2017). Enhancing Programs to Integrate Tertiary Outbound Mobility Experiences (EPITOME): Final Report 2016. Western Sydney University. https://doi.org/10.4225/35/588805fa8dd28

Hakim, A., \& Kumala, F. (2016). Pengembangan Karakter Melalui Kegiatan Outbound. Jurnal Moral Kemasyarakatan, 1(2), 173-182. https://doi.org/10.21067/jmk.v1i2.1534

Mahendra, A. (2018). Program PDS UPI dalam Pendidikan Jasmani: Membumikan Penjas Bernuansa Mendidik. TEGAR: Journal of Teaching Physical Education in Elementary School, 2(1), 1. https://doi.org/10.17509/tegar.v2i1.13774

Winarno. (2011). Metodologi Penelitian Dalam Pendidikan Jasmani. Malang: Media Cakrawala Utama Press.

Yunaida, H., \& Rosita, T. (2018). Outbound Berbasis Karakter Sebagai Media Pembelajaran Anak Usia Dini (Studi Kasus Di Tk Aisyiyah 6 Kota Bandung). Jurnal COMM-EDU, 1(1), 30-37. 